\title{
Matéria
}

ISSN 1517-7076

Revista Matéria, v. 13, n. 2, pp. 316 - 321, 2008

http://www.materia.coppe.ufrj.br/sarra/artigos/artigo10921

\section{Eletrochemical hydrogenation of Nd2Fe17 and Nd2Fe15.5Ga1.5}

\author{
DE MELO, A.C. ${ }^{\text {I }}$; ZAMPRONIO, M.A. ${ }^{\text {I }}$; COLUCCI, C.C. ${ }^{\text {I }}$; DESTEFANO, A. ${ }^{\text {I }}$; SOUZA, N. E. ${ }^{\text {II }}$; \\ ALVES, C.S. ${ }^{\text {III }}$; \\ ${ }^{\mathrm{I}}$ Universidade Estadual de Maringá, Departamento de Física, Maringá - Brazil \\ e-mails:mmelo@,dfi.uem.br,mazampro@,dfi.uem.br,ccolucci@dfi.uem.br. \\ destefano@dfi.uem.br. \\ ${ }^{\text {II }}$ Universidade Estadual do Centro-Oeste, Departamento de Ciências, Irati - Brazil \\ e-mail: eloifire@yahoo.com.br \\ ${ }^{\text {III }}$ Universidade Estadual de Maringá, Departamento de Engenharia Mecânica, Maringá - Brazil \\ Laboratório de Materiais Especiais - DFI/UEM \\ Av. Colombo 5790 - CEP 87020-900, Maringá - Paraná - Brasil \\ e-mail: csalves@uem.br
}

\begin{abstract}
A study of hydrogenation of the metallic alloys $\mathrm{Nd}_{2} \mathrm{Fe}_{17}$ and $\mathrm{Nd}_{2} \mathrm{Fe}_{1,5} \mathrm{Ga}_{1.5}$ using electrochemical hydrogenation in a solution of $0.1 \mathrm{~N} \mathrm{NaOH}$ at $313 \mathrm{~K}$ and $2 \mathrm{~A} / \mathrm{m}^{2}$ current density is presented. The pure and electrochemical hydrogenated samples were characterized by Mössbauer spectroscopy and X-ray diffraction. Analysis after hydrogen desorption reveal no presence of new phases or oxides. Similarities and differences with gas hydrogenation are observed.
\end{abstract}

Keywords: hydrogenation, electrochemical methods and Mössbauer effect.

\section{INTRODUCTION}

The first report of the influence of absorbed hydrogen on the magnetic properties of a rare-earth intermetallic material was given by Zijlstra and Westendorp [1]. Several results of hydrogenation of rareearth intermetallic systems have become available in recent years. Hydrogenation in magnetic materials leads to improvements not only via interstitial modification, but also due to changes of physical properties and the structure of metals as result of the hydrogen treatment.

Since the early work of Coey et al. [2,3], the interest in the $\mathrm{R}_{2} \mathrm{Fe}_{17}$ compounds and their interstitials with hydrogen and nitrogen has rapidly grown up because they are good candidates for permanent magnets. Despite high values of the Curie temperatures, saturation magnetization and anisotropy field [3], the technical application of these materials is limited by their poor thermal stability. Shen et al. [4] found that by partially substituting Fe by Ga the phase can be stabilized to temperatures above $1200 \mathrm{~K}$. The utilization of the hydrogen- disproportionation- desorption-recombination process (HDDR) [5,6] is an effective way for obtaining high coercive magnets. Unfortunately, the substitution of $\mathrm{Fe}$ by $\mathrm{Ga}$ also stabilizes other compounds against disproportionation by hydrogen [ㄱ, $\underline{8}]$. Thus, an improvement of the hydrogen treatment of $\mathrm{R}_{2} \mathrm{Fe}_{17}$ as pure phase and with Ga are very desirable.

Until now the best hydrogen treatment was performed at high temperatures and at high hydrogen pressure $[1,2, \underline{3}, \underline{9}]$. However, these conditions, as described above, can facilitate the formation of new undesired phases and also oxides. Gas hydrogenation requires expensive and complicated equipment. In contrast, electrochemical methods are very simple, not expensive and can be performed at room temperature.

The phase $\mathrm{R}_{2} \mathrm{Fe}_{17}$ contains more than 80 at \% iron and is ideally suited to be studied by Mössbauer spectroscopy $[\underline{10}, \underline{11}]$. Therefore, several studies of hydrogenation of $\mathrm{R}_{2} \mathrm{Fe}_{17}$ were successfully performed in the last years mainly to make correlations between hyperfine magnetic fields and the hydrogen concentration [12], [9]. In this paper is presented a study of electrochemical hydrogenation on $\mathrm{Nd}_{2} \mathrm{Fe}_{17}$ and $\mathrm{Nd}_{2} \mathrm{Fe}_{15.5} \mathrm{Ga}_{1.5}$ using Mössbauer Spectroscopy. 


\section{EXPERIMENTAL}

Bulk samples of $\mathrm{Nd}_{2} \mathrm{Fe}_{17}$ and $\mathrm{Nd}_{2} \mathrm{Fe}_{15.5} \mathrm{Ga}_{1.5}$ were prepared by arc-melting from starting materials of $99,9 \%$ purity. The alloys were melted at least three times to ensure homogeneity. After arc melting, the polycrystalline specimens were sealed into evacuated quartz tubes and annealed (1073 K $-72 \mathrm{~h})$. X-ray diffraction was employed to determine the phase composition, structure and lattice parameters. The alloys consisted of the $\mathrm{Th}_{2} \mathrm{Zn}_{17}$ structure phase with low traces of alpha-Fe, which is common to be found [2]. Then, all samples were cut with a thickness of $1 \mathrm{~mm}$ and metallographically polished. Potentiodynamic polarization curves were obtained in an electrochemical cell similar to one of the set-ups described by Zampronio et al. [13]. The tests were conducted at $313 \mathrm{~K}$, using a solution of $0.1 \mathrm{~N} \mathrm{NaOH}$ as electrolyte, a counter-electrode of $\mathrm{Pt}$ and a saturated calomel as reference electrode.

The samples of $\mathrm{Nd}_{2} \mathrm{Fe}_{17}$ and $\mathrm{Nd}_{2} \mathrm{Fe}_{15.5} \mathrm{Ga}_{1.5}$ were then hydrogenated in a simple experimental setup, as shown in Figure 1. The electric contact for the sample was made with a cable on one face of the sample and electrically isolated from the electrolyte solution, the hydrogenation process happening at the opposite face. The sample was cathodic polarized in a solution of $0.1 \mathrm{~N} \mathrm{NaOH}$ at $313 \mathrm{~K}$ and $2 \mathrm{~A} / \mathrm{m}^{2}$ current density (see potentiodynamic polarization results in Figure 2). Hydrogen permeating through the fresh surface leads to the fracture of the specimen in a fine powder. The powder in the electrolyte solution was dried and characterized by X-Ray Diffractometry and Mössbauer Spectroscopy.

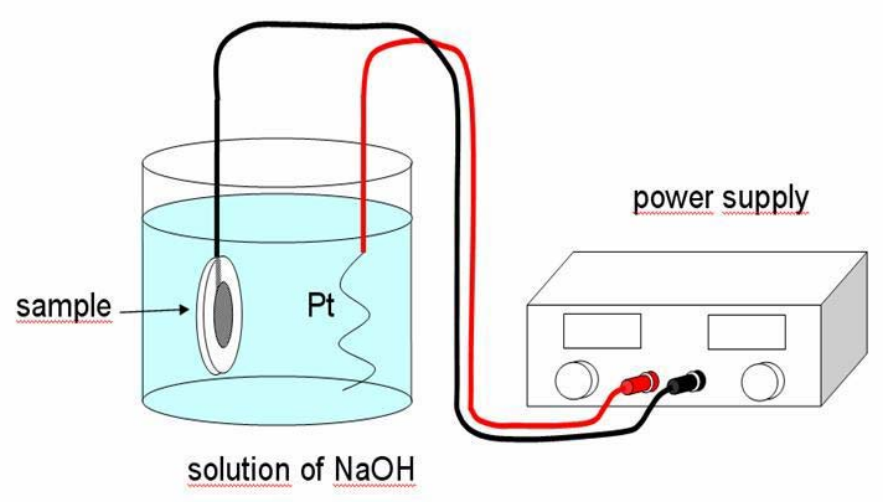

Figure 1: Experimental Setup of the electrochemical hydrogenation.

\section{$3 \quad$ RESULTS AND DISCUSSION}

Potentiodynamic polarization curves are used to characterize the possible chemical reaction in dependence of the applied electrical potential. Figure 2 shows a potentiodynamic polarization curve of $\mathrm{Nd}_{2} \mathrm{Fe}_{17}$. The behavior is quite similar to that found for steel [13]. The potential in open circuit was $-0.487 \mathrm{~V}$ vs. SCE and the potential of generation of hydrogen was $-1.200 \mathrm{~V}$ vs. SCE. 


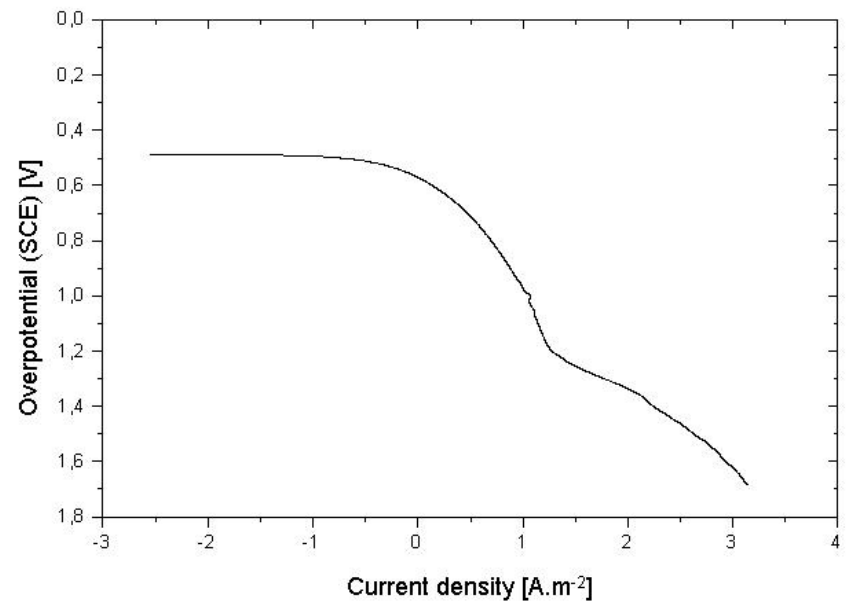

Figure 2: Potentiodynamic polarization curve of $\mathrm{Nd}_{2} \mathrm{Fe}_{17}$.

Thus, in order to obtain the electrochemical hydrogenation it was used a potential of $-1.440 \mathrm{~V}$ vs. SCE, which is $20 \%$ higher than the potential of generation of hydrogen. The potential of $-1.440 \mathrm{~V}$ vs. SCE corresponds to a current density of $2 \mathrm{~A} / \mathrm{m}^{2}$.

The electrochemical hydrogenation was performed using the current density obtained by potentiodynamic polarization test. The powder in the electrolyte solution was dried and characterized by XRay Diffractometry and Mössbauer Spectroscopy.

The Mössbauer effect spectra obtained at room temperature of $\mathrm{Nd}_{2} \mathrm{Fe}_{17}$ samples in the initial state, after hydrogenation and dehydrogenation, are shown in Figure 3.

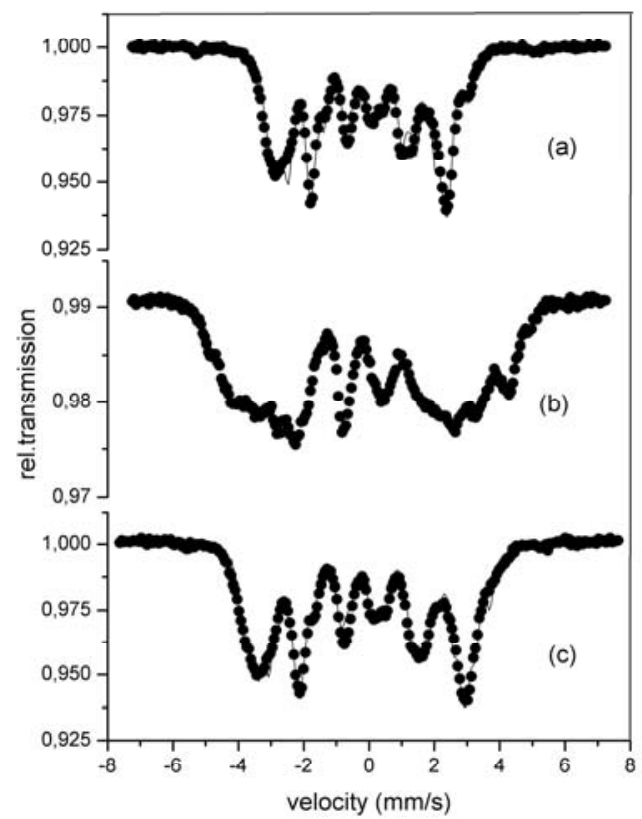

Figure 3: The Mossbauer spectra of a) initial state $\mathrm{Nd}_{2} \mathrm{Fe}_{17}$, b) eletrochemically hydrogenated $\mathrm{Nd}_{2} \mathrm{Fe}_{17}$ and c) dehydrogenated $\mathrm{Nd}_{2} \mathrm{Fe}_{17}$. 
The obtained spectra from the $\mathrm{Nd}_{2} \mathrm{Fe}_{17}$ sample in the initial state (Figure 3a) is similar to those reported by Grandjean et al. [12] Hu et al. [14], Al-Omari et al. [15] and J. Shobaki et al. [16]. The spectra were fit with seven sextets corresponding to seven magnetically inequivalent iron sites. The found average hyperfine magnetic field is $178 \mathrm{kOe}$.

The spectra from $\mathrm{Nd}_{2} \mathrm{Fe}_{17}$ in the hydrogenated state (Figure $3 \mathrm{~b}$ ) show a larger value of the magnetic hyperfine field than the spectra without hydrogen. A broadening of the lines is also observed. The increase of the hyperfine magnetic fields is related to the lattice expansion due the increase of the hydrogen concentration in similar compounds [12], [16], [17]. Due to these broad lines the spectrum was well fitted with two groups of seven subspectra and the average hyperfine magnetic fields are $178 \mathrm{kOe}$ and $280 \mathrm{kOe}$. The first group of subspectra has the same field found in the sample without hydrogen. The hyperfine parameters of the second group are quite similar to that of $\mathrm{Nd}_{2} \mathrm{Fe}_{17} \mathrm{H}_{5}$ obtained at $300 \mathrm{~K}$ by Grandjean et al. [12]. This indicates that there is a distribution of hydrogen concentration over 5 hydrogen / f.u.

After dehydrogenation, the Mössbauer spectra are typical of the 2:17 phase (Figure 3c). The sample shows a magnetic hyperfine field $20 \%$ higher than found in the initial samples. This indicates the presence of hydrogen in the sample. The Mössbauer spectra obtained at room temperature of $\mathrm{Nd}_{2} \mathrm{Fe}_{15.5} \mathrm{Ga}_{1.5}$ samples in the initial state, after electrochemical hydrogenation and dehydrogenation are shown in Figure 4.

The obtained spectrum from the $\mathrm{Nd}_{2} \mathrm{Fe}_{15.5} \mathrm{Ga}_{1.5}$ sample in the initial state (Figure 4a) is similar to that reported by J. Shobaki et al. [16]. Like the spectra from the initial sample without gallium the fitting was done with seven sextets. The found average hyperfine magnetic field is $220 \mathrm{kOe}$. The substitution of $\mathrm{Fe}$ atoms by $\mathrm{Ga}$ increases the average hyperfine magnetic field [14].

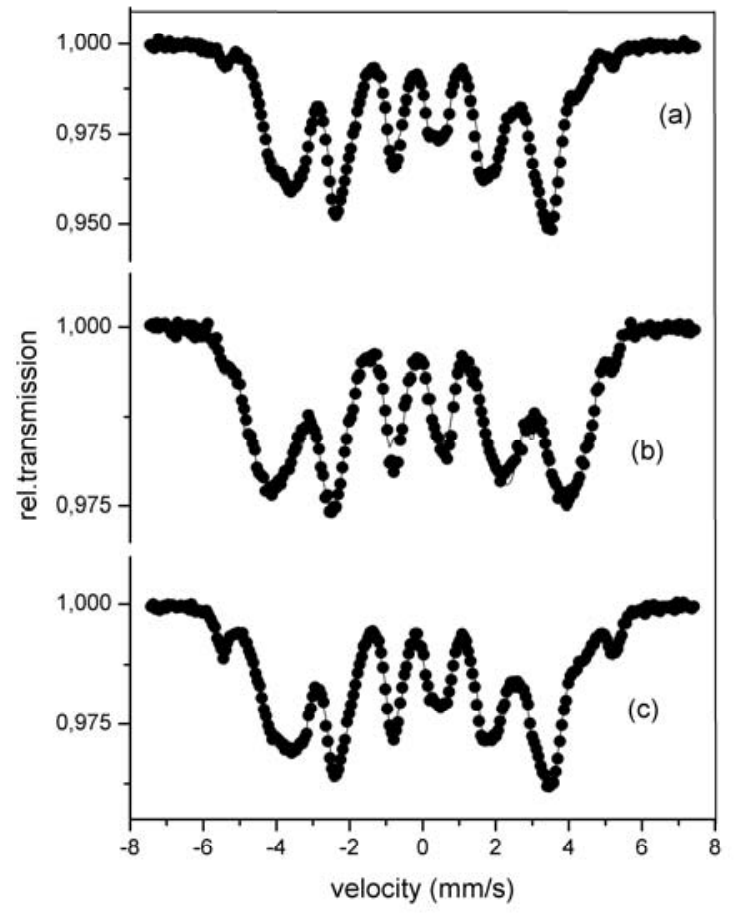

Figure 4: The Mossbauer spectra of a) initial state $\mathrm{Nd}_{2} \mathrm{Fe}_{15.5} \mathrm{Ga}_{1.5}$, b) eletrochemically hydrogenated $\mathrm{Nd}_{2} \mathrm{Fe}_{15.5} \mathrm{Ga}_{1.5}$ and c) dehydrogenated $\mathrm{Nd}_{2} \mathrm{Fe}_{15.5} \mathrm{Ga}_{1.5}$.

The spectrum of the hydrogenated sample with gallium can be also well fitted with only seven subspectra (Figure 4b). The found average hyperfine magnetic field is $248 \mathrm{kOe}$, which is higher than the value $220 \mathrm{kOe}$, found in the sample without hydrogen. The hyperfine field of $248 \mathrm{kOe}$ is almost in the saturation limit [12]. As discussed above, the increase of the hyperfine magnetic field can be related to the presence of hydrogen.

The Mössbauer spectra from the dehydrogenated sample with gallium (Figure 4c) are similar to that found from the initial sample with gallium before the hydrogenation. 
In all dehydrogenated samples the presence of oxides or another phase is not observed. This indicates also that the electrochemical hydrogenation of the samples is performed very well.

Also, in all hydrogenated samples a small increase in the isomer shift is observed. This is due to a decrease in the s-electron density at the Fe nucleus, which can be attributed to the expansion of the unit cell volume $[\underline{12}, 17]$ and the high electronegativity of hydrogen.

Another effect from the electrochemical hydrogenation observed in all the samples is the powdering of the samples. A cracking and partial powdering process based on gas hydrogenation is widely used in manufacturing permanent magnetic. Despite the observed broad distribution of the particle size, preliminary measurements suggest that the particle size can be better controlled at low current density. The effect of the electrolyte composition and temperature on the particle size distribution must be checked.

\section{CONCLUSIONS}

The electrochemical hydrogenation of rare-earth intermetallic compounds is simple, providing the possibility of a hydrogenation of materials at room temperature. Usually a gas hydrogenation is done at high temperatures. Mössbauer spectroscopy shows very close similarities between the results from electrochemical and gas hydrogenation. The electrochemical hydrogenation can also leads to the fracture of the sample of intermetallic material into a fine powder.

The hydrogenation performed in the $\mathrm{H}_{2}$ gas atmosphere is until now better reproducible when compared with that in electrolyte solution. Although, the electrochemical hydrogenation in different current densities and other electrolyte solutions may be performed to improve the results. In addition, the electrochemical hydrogenation process is more reliable from technological point of view. Thus, our initial results indicate that the electrochemical hydrogenation process is another way to perform hydrogenation process of intermetallic alloys.

\section{ACKNOWLEDGMENTS}

We thank Prof. Dr. J. Litterst and Dr. H. Bremers for the use of their facilities at TU-Braunschweig, and the assistance Funding for this work was provided by the Brazilian agencies CAPES, CNPq and FUNDACAO ARAUCARIA.

\section{REFERENCES}

[1] ZIJLSTRA, H., WESTENDORP, F.F., "Influence of hydrogen on magnetic properties of SmCo ", Solid $^{\circ}$ State Commun, v. 7, pp. 857, 1969.

[2] XIAN-ZHONG, W., DONNELly, K., COEY, J.M.D., CHEVALIER, B., ETOURNEAU, J., BERLUREAU, T., "Hydrogen absorption and desorption in $\mathrm{Nd}_{2} \mathrm{Fe}_{17}$ and $\mathrm{Sm}_{2} \mathrm{Fe}_{17}$ ", Journal Material Science, v. 23, pp. 329-331, 1988.

[3] COEY, J.M.D., SUN, H., "Improved magnetic-properties by treatment of iron-based rare-earth intermetallic compounds in ammonia”, Journal of Magnetism and Magnetic Materials, v. 87, pp. L251-L254, 1990.

[4] SHEN, B.G., KONG, L.S., WANG, F.W., CAO, L., "Structure and magnetic-properties of $\mathrm{Sm}_{2} \mathrm{Fe}_{14} \mathrm{Ga}_{3} \mathrm{C}_{\mathrm{x}}$ $(\mathrm{x}=0-2.5)$ compounds prepared by arc melting", Applied Physics Letters, v. 63, pp. 2288, 1993.

[5] RAGG, O.M., KEEGAN, G., NAGEL, H., HARRIS, I.R., "The HD and HDDR processes in the production of Nd-Fe-B permanent magnets", International Journey of Hydrogen Energy, v. 22, pp. 333, 1997.

[6] CHRISTODOULOU, C.N., TAKESHITA, T., " $\mathrm{Sm}_{2} \mathrm{Fe}_{17}$-nitride-based permanent-magnets produced by the hydrogenation decomposition desorption recombination (HDDR) process", Journal of Alloys and Compounds, v.196, pp. 155, 1993. 
[7] KUBIS, M., CAO, L., MULLHER, K-H., SHULTZ, L., "Hydrogenation disproportionation desorption recombination on $\mathrm{Sm}_{2} \mathrm{Fe}_{17-\mathrm{x}} \mathrm{Ga}_{\mathrm{x}}$ with high $\mathrm{Ga}$ content $(\mathrm{x}>=1)$ by means of reactive grinding", Journal of Physics D: Applied Physics, v. 30, pp. L51, 1997.

[8] KUBIS, M., CAO, L., GEBEL, B., MULlER, K-H., SHULTZ, L., "Preparation of $\mathrm{Sm}_{2} \mathrm{Fe}_{17-\mathrm{x}} \mathrm{Ga}_{x} \mathrm{~N}_{\mathrm{y}} / \mathrm{C}_{\text {-y }}$ magnets by a hydrogenation-disproportionation-desorption-recombination process", Journal of Applied Physics, v. 81, pp. 6485, 1997.

[9] GOLTSOV, V.A., "Hydrogen treatment (processing) of materials: current status and prospects", Journal of Alloys and Compounds, v. 293-295, pp. 844-857, 1999.

[10] CADOGAN, J.M., "Mossbauer spectroscopy and rare-earth permanent magnets", Journal of Physics D: Applied Physics v. 29 - 9, pp. 2246-2254, 1996.

[11] QI QN, SUN H.,COEY, J.M.D., "Mossbauer studies of interstitial rare-earth iron intermetallics", Hyperfine Interactions, v. 68, pp. 27-38, 1991.

[12] GRANDJEAN, F., LONG, G.J., MISHRA, S., PRINGLES, O.A., ISNARD, O., MIRAGLIA, S., FRUCHART, D., "A Mossbauer-effect study of the interstitial hydrides and nitride of $\mathrm{Nd}_{2} \mathrm{Fe}_{17}$ ", Hyperfine Interactions, v. 95, pp. 277-290, 1995.

[13] ZAMPRONIO, M.A., FASSINI, F.D., DE MIRANDA, P.E.V., "Design of ion-implanted hydrogen contamination barrier layers for steel”, Surface and Coatings Technology, v. 70, pp. 203-209, 1995.

[14] HU, Z., YELON, W.B., MISHRA, S., LONG, G.J., PRINGLE, O.A., MIDDLETON, D.P., BUSCHOW, K.H.J., GRANDJEAN, F., "A magnetic, neutron-diffraction, and Mossbauer spectral study of $\mathrm{Nd}_{2} \mathrm{Fe}_{15} \mathrm{Ga}_{2}$ and the $\mathrm{Tb}_{2} \mathrm{Fe}_{17-\mathrm{x}} \mathrm{Ga}_{\mathrm{x}}$ solid-solutions", Journal of Applied Physics, v. 76, n. 1, pp. 443, 1994.

[15] AL-OMARI, I.A., JASWAL, S.S., SINGLETON, E.W., SELlMYER, D.J., ZHENG, Y., HAPJIPANAYIS, G.C., "Mossbauer study of permanent-magnet materials - $\mathrm{Sm}_{2} \mathrm{Fe}_{17-\mathrm{x}} \mathrm{Ga}_{\mathrm{x}} \mathrm{C}_{\mathrm{y}}$ compounds", Journal of Magnetism and Magnetic Materials, v. 151, pp. 145-149, 1995.

[16] SHOBAKI, J., AL-OMARI, I.A., HASAN, M.K., AZEZ, K.A., MAHMOOD, S.H., SELLMYER, D.J., Physica, "Magnetic, X-ray diffraction, and Mossbauer spectroscopy studies of $\mathrm{Nd}_{2} \mathrm{Fe}_{15} \mathrm{Ga}_{2} \mathrm{C}_{\mathrm{x}}$ magnets", v. B321, pp. 173-177, 2002.

[17] RUPP, B., WIESINGER, G., "Magnetic and structural-properties of a novel ternary hydride $-\mathrm{Nd}_{2} \mathrm{Fe}_{17} \mathrm{H}_{\mathrm{x}}$ $(0=<\mathrm{x}=<5)$ ", Journal of Magnetism and Magnetic Materials, v. 17, pp. 269, 1988. 